\title{
Carbohydrate Mediation of the Biological Activities of the Glycolipoprotein of Pseudomonas aeruginosa
}

\author{
By THOMAS ORR, LEILA H. KOEPP AND PASQUALE F. BARTELL* \\ Department of Microbiology, University of Medicine and Dentistry, New Jersey Medical School, \\ Newark, New Jersey 07103, U.S.A.
}

(Received 6 January 1982; revised 13 April 1982)

\begin{abstract}
The glycolipoprotein (GLP) extracted from the surface slime of Pseudomonas aeruginosa produces effects in mice similar to those of the viable cell. The lethal activity has been located in the lipid moiety; however, degradation of the carbohydrate moiety with sodium metaperiodate reduced the antigenicity and abolished the lethality of the GLP. Similar degradation with a phage-induced polysaccharide depolymerase reduced the antigenicity only slightly but reduced the lethality over $60 \%$. The neutral sugar composition of the isolated polysaccharide moiety was shown to be that of the parental GLP. Of the component neutral sugars, mannose and its derivatives were capable of inhibiting the agglutination of erythrocytes coated with GLP. Inhibition also occurred with a soluble mannose polymer from the cell walls of yeast. Antiserum to GLP and to its isolated polysaccharide moiety agglutinated yeast cells, whereas antiserum to a glycolipid fragment of the GLP lacking mannose did not. The lethality of the GLP was reduced by degradation with $\alpha$-mannosidase or by blocking the mannose residues with concanavalin $A$, and the glycolipid fragment showed less lethality than the native GLP. We conclude that mannose, in addition to being an immunodominant sugar, is an effector sugar in the expression of GLP lethality.
\end{abstract}

\section{INTRODUCTION}

Pseudomonas aeruginosa produces severe and sometimes life-threatening infections as a consequence of unknown factors in patients suffering from cystic fibrosis, burns and cancer (Doggett, 1979). Accordingly, the basis for pseudomonal pathogenesis continues to be an area of active investigation. As an aspect of this investigation, the glycolipoprotein (GLP) is a subcellular fraction of interest.

Derived from the extracellular slime layer, which is characteristic of the species (Haynes, 1951), the GLP is clearly distinguishable from cell wall components such as the lipopolysaccharide (Sensakovic \& Bartell, 1974; Castillo \& Bartell, 1974), and it elicits pathogenic effects in mice characteristic of infection with viable cells (Sensakovic \& Bartell, 1974). Fractionation of the GLP has yielded a series of components of increasing simplicity and of varying biological activity. As a result, the protective immunogenic activity of the GLP is specified by the carbohydrate moiety (Koepp et al., 1981 $a$ ), and the leukopenic and lethal activity in the lipid (Sensakovic \& Bartell, 1975; Koepp et al., 1981 b). When stripped chemically or enzymically of the protein moiety, the GLP apparently retains its biological activities (Sensakovic \& Bartell, 1975; Koepp et al., 1981 b). So, the function of the protein remains in question.

Recently, we suggested that the carbohydrate moiety is required for full expression of the lethality of the lipid moiety, although the carbohydrate moiety in itself does not produce sublethal toxicity, let alone lethality (Koepp et al., 1981a). The evidence for this hypothesis is indirect, relying on an analysis of carbohydrate residues on fragments of the GLP largely composed of lipid. In the present study, we report more direct evidence supporting this hypothesis. In addition, we present data indicating that mannose is an effector monosaccharide 
underlying the carbohydrate requirement for lethality, as well as representing an immunodeterminant sugar in the carbohydrate moiety.

\section{METHODS}

Micro-organisms. Pseudomonas aeruginosa strain BI was originally isolated from a clinical urine specimen and has been described previously (Bartell et al., 1966). Organisms were grown on Trypticase soy broth and Trypticase soy agar (TSB and TSA; BBL). Stock cultures were maintained on TSA slants at $4{ }^{\circ} \mathrm{C}$ and on TSA slants covered with sterile paraffin oil at room temperature. Saccharomyces cerevisiae strain Y185 (genotype mat a/mat $\alpha$ ade $2 /+$ $h i s 2 /+h i s 8 /+l y s 2 /+$ ) was a gift of David Kaback (Department of Microbiology, New Jersey Medical School) and was grown and maintained on a standard medium consisting of $1 \%(\mathrm{w} / \mathrm{v})$ yeast extract, $2 \%(\mathrm{w} / \mathrm{v})$ peptone, $2 \%$ $(\mathrm{w} / \mathrm{v})$ dextrose and $2 \%(\mathrm{w} / \mathrm{v})$ agar.

Extraction of glycolipoprotein (GLP) and its fragments. GLP was prepared from $18 \mathrm{~h}$ cultures of strain $\mathrm{BI}$ grown on sheets of dialyser tubing (molecular weight retention $>6000 ;$ A. H. Thomas Co., Philadelphia, Pa., U.S.A.) overlaying TSA plates and processed as previously reported (Bartell et al., 1970; Sensakovic \& Bartell, 1974). Crude slime was separated from the cells by gentle agitation in $0.15 \mathrm{M}-\mathrm{NaCl}$ and clarified by centrifugation at $12000 \mathrm{~g}$ for $30 \mathrm{~min}$. The supernatant fluid was dialysed against distilled water, and the GLP fraction was precipitated with 3 vol. $95 \%$ ethanol containing $10 \%(\mathrm{w} / \mathrm{v})$ sodium acetate and $1 \%(\mathrm{v} / \mathrm{v})$ glacial acetic acid at $4{ }^{\circ} \mathrm{C}$. The precipitate was sedimented, resuspended in distilled water and dialysed against distilled water. The ethanol precipitation was repeated, and the precipitate, dissolved in distilled water, was clarified by centrifugation at $27000 \mathrm{~g}$ for $30 \mathrm{~min}$ and dialysed at $4{ }^{\circ} \mathrm{C}$ against approximately $20 \mathrm{vol}$. distilled water. The extract was centrifuged at $105000 \mathrm{~g}$ for $3 \mathrm{~h}$, and the supernatant fluid was saved and lyophilized as the GLP. The yield from 100 Petri dishes $(150 \times 15 \mathrm{~mm})$ was $500 \mathrm{mg}$. The antigenic homogeneity of individual lots of GLP was monitored in Ouchterlony radial, double-diffusion plates where a single precipitin band was produced against antiserum capable of forming two bands against crude slime.

Purity of the GLP and its distinctness from other wall components were demonstrated by several criteria. The GLP eluted as a single peak from anion-exchange DEAE-cellulose (Cellex D, Bio-Rad) at 0.3 M-potassium chloride (Sensakovic \& Bartell, 1974). The sedimentation profile of the GLP, as visualized by Schlieren optics, was characteristic of a homogeneous, monodisperse macromolecule (Sensakovic \& Bartell, 1974). Further, the neutralsugar composition of GLP differed from that of the homologous lipopolysaccharide by containing mannose and galactose, both of which were absent from the lipopolysaccharide (Castillo \& Bartell, 1974).

The isolated polysaccharide moiety of the GLP was obtained as reported by boiling $1 \%(\mathrm{w} / \mathrm{v})$ GLP for $90 \mathrm{~min}$ in $1 \%(\mathrm{v} / \mathrm{v})$ acetic acid and collecting the polysaccharide from the aqueous phase (Koepp et al., 1981a). The glycolipid fragment was extracted from the GLP by hot-phenol treatment (Fenson \& Gray, 1969). Rehydrated GLP was mixed with an equal volume of $90 \%(\mathrm{w} / \mathrm{v})$ neutral phenol at $65^{\circ} \mathrm{C}$ for $90 \mathrm{~min}$. The aqueous phase was adsorbed to and eluted from anion-exchange DEAE-cellulose as previously reported (Koepp et al., $1981 \mathrm{~b}$ ).

$G L C$. Neutral monosaccharides were analysed by GLC and the resultant peaks were identified on the basis of co-chromatography with known standards. For analysis of the polysaccharide $10 \mathrm{mg}$ of GLP was hydrolysed in 1 $\mathrm{ml}$ of $6 \mathrm{M}-\mathrm{HCl}$ for $2 \mathrm{~h}$ at $100^{\circ} \mathrm{C}$. The sugars were converted to alditol acetates (Spiro, 1972) and the final solution containing the sugar derivatives was injected directly into a glass column $(180 \mathrm{~cm} \times 2 \mathrm{~mm})$ filled with $3 \%(\mathrm{w} / \mathrm{v})$ SP-2340 on 100-120 mesh Supelcoport (Supelco, Bellefonte, Pa., U.S.A.) and analysed by a single-flame ionization detector in a Sigma 3 (Perkin-Elmer) gas chromatograph. Conditions for analysis were as follows: column temperature, $230^{\circ} \mathrm{C}$; inlet temperatures, $200^{\circ} \mathrm{C}$; flow rate, $20 \mathrm{ml}^{-1}$.

Periodate degradation. The procedure was based on the method of Spiro (1966). GLP (50 mg) was rehydrated in $50 \mathrm{ml}$ of $0.1 \mathrm{M}$-sodium acetate buffer, $\mathrm{pH} 4.0$ and sodium metaperiodate was added to a concentration of $0.03 \mathrm{M}$. After $48 \mathrm{~h}$ in the dark at $4{ }^{\circ} \mathrm{C}$ excess periodate was reduced with $1.5 \mathrm{ml}$ of undiluted ethylene glycol. The treated GLP was dialysed extensively in the cold, first against $0.1 \mathrm{M}-\mathrm{NaCl}$ and then against deionized water. The nondiffusible material was lyophilized and stored in vacuo over phosphorus pentoxide until use.

Polysaccharide depolymerase 2 . The depolymerase was prepared by methods described previously (Castillo \& Bartell, 1974). Crude enzyme was extracted from exponential phase cultures of strain BI infected with phage 2 growing in $0.65 \%(\mathrm{w} / \mathrm{v})$ agar in TSB overlaying TSA plates. Harvested cultures were homogenized in a Waring blender with $10 \%(\mathrm{v} / \mathrm{v})$ chloroform and clarified by centrifugation at $12000 \mathrm{~g}$ for $10 \mathrm{~min}$. The depolymerase was precipitated by the addition of ammonium sulphate to $45 \%$ saturation, and the redissolved sediment was dialysed in the cold until the dialysing buffer was negative for sulphate, as determined by the absence of a precipitate in an acidified sample to which $0.2 \mathrm{M}$-barium chloride was added. The preparation was frozen and stored in $1.0 \mathrm{ml}$ amounts at $-20^{\circ} \mathrm{C}$. Depolymerase activity was assayed by measuring the release of hexosamine from purified GLP, with the unit of activity defined as nmol hexosamine released $\min ^{-1}\left(\mathrm{mg}^{\mathrm{d} y} \text { wt protein }\right)^{-1}$. Preparations contained approximately 50 units $\mathrm{ml}^{-1}$. For depolymerization of GLP, $1 \mathrm{ml}$ of undiluted depolymerase was added to $30 \mathrm{mg}$ of GLP rehydrated in $0.1 \mathrm{M}$-phosphate buffered saline (PBS) at pH 7.5 and incubated at $37^{\circ} \mathrm{C}$ for $24 \mathrm{~h}$ 
with shaking. After extensive dialysis against deionized water, the treated GLP was freeze-dried and stored in racuo over phosphorus pentoxide until rehydrated for use.

Animals. New Zealand white male rabbits weighing 3 to $4 \mathrm{~kg}$ were housed individually. Male Swiss white mice (18 to $20 \mathrm{~g}$ ) were housed 5 to 10 per cage. All animals were supplied with water and Purina chow ad libitum.

Preparation and assay of antisera. Antisera were produced according to the following schedule: on day 0 , the rabbits received subcutaneous injections of $0.5 \mathrm{ml}$ at four separate sites with a total of $2 \mathrm{mg}$ of the appropriate preparation in an equal volume of PBS at pH 7.0 and Freund's incomplete adjuvant (Difco). Antiserum to the isolated polysaccharide was prepared similarly after coupling the polysaccharide to bovine serum albumin (Koepp et al., $1981 \mathrm{a}$ ). Bovine serum albumin ( $\mathrm{g}$ ) was dissolved in $100 \mathrm{ml}$ of absolute methanol followed by the addition of $0.84 \mathrm{ml}$ of $12 \mathrm{M}-\mathrm{HCl}$. After $3 \mathrm{~d}$ in the dark with occasional mixing, the precipitate was collected by centrifugation at $5000 \mathrm{~g}$ for $15 \mathrm{~min}$. After washing with methanol, the precipitate was dissolved in distilled water and dialysed against several changes of distilled water and freeze-dried. Methylated albumin $(30 \mathrm{mg})$ was dissolved in $1 \mathrm{ml}$ distilled water and added to $10 \mathrm{mg}$ of polysaccharide dissolved in $4 \mathrm{ml}$ PBS (Kozel \& Cazin, 1974). This mixture was diluted to the appropriate level for immunization of rabbits. Groups of three anaesthetized rabbits were bled on day 0 for normal control sera and 18 to $20 \mathrm{~d}$ afterwards. Sera to the same antigen with satisfactory passivehaemagglutination titres were pooled.

Formalinized sheep red blood cells (Difco) were sensitized by incubating a $5 \%(\mathrm{v} / \mathrm{v})$ suspension of cells in PBS at $\mathrm{pH} 7 \cdot 0$, with an equal volume of GLP $\left(200 \mu \mathrm{g} \mathrm{ml}^{-1}\right)$ at room temperature for $30 \mathrm{~min}$. The sensitized cells were washed three times in PBS and resuspended to a concentration of $5 \%(\mathrm{v} / \mathrm{v})$ in PBS. Sensitized cells $(0.05 \mathrm{ml})$ were added to $0.5 \mathrm{ml}$ serial dilutions of antiserum, mixed well, allowed to settle at room temperature for $2 \mathrm{~h}$ and read. The end-point was expressed as the reciprocal of the highest serum dilution resulting in a positive haemagglutination pattern. The titre of the serum used in the present work was 320 .

Passive-haemagglutination inhibition test. The GLP fraction to be tested for inhibitory capacity was added $(10 \mu \mathrm{g}$ in $0.1 \mathrm{ml}$ of PBS, $\mathrm{pH} 7.0$ ) to $0.5 \mathrm{ml}$ dilutions of antiserum. After incubation at room temperature for $60 \mathrm{~min}, 0.05 \mathrm{ml}$ of the sensitized red blood cells was added to each tube and the haemagglutination titre was determined after a $2 \mathrm{~h}$ incubation period at room temperature. The monosaccharides and mannan from Sigma were similarly tested at 5 $\mathrm{mg} \mathrm{ml}^{-1}$.

Lethality and toxicity studies. Challenge doses of native and degraded GLP were rehydrated in PBS at pH $7 \cdot 2$ and injected intraperitoneally into groups of 5 or 10 mice per dose. Injected mice were observed for $7 \mathrm{~d}$. The $50 \%$ lethal dose $\left(\mathrm{LD}_{50}\right)$ was determined by the method of Reed \& Muench (1938); average values from three to five tests are in general presented. Exceptions to this rule were: periodate-treated GLP determinations were repeated only twice since the highest concentrations tested were not lethal or toxic; depolymerase-treated GLP and $\alpha$ mannosidase-treated GLP determinations were repeated only twice since the repeated experiments were in exact agreement. Standard errors of the means or $95 \%$ confidence limits of the means were calculated for all $50 \%$ lethal dose values, and the significance of differences in survival levels was assessed by the $t$ test (Batson, 1956). Mice were observed for signs of a toxic manifestation such as ruffled hair, ocular discharge, lethargy and diarrhoea.

Yeast cell aggregation. Yeast cell aggregation was determined. One drop of a turbid suspension of S. cerevisiae in PBS at pH 7.0 was mixed with one drop of antiserum and gross aggregation was observed.

$\alpha$-Mannosidase treatment of GLP. GLP was treated with $\alpha$-mannosidase according to the procedure of Maisch \& Calderone (1981). Briefly, GLP (150 mg, dry wt) was dissolved in $40 \mathrm{ml}$ of $0.05 \mathrm{~m}$-potassium phosphate buffer, $\mathrm{pH}$ 6.8 , containing $10 \mu \mathrm{M}$-calcium chloride $\mathrm{ml}^{-1}$ and $50 \mu \mathrm{g}$ bovine serum albumin $\mathrm{ml}^{-1}$. To this, $2 \mathrm{mg}$ (approximately $50 \mathrm{U}) \alpha$-mannosidase (Sigma) was added. The mixture was incubated at $37^{\circ} \mathrm{C}$ for $24 \mathrm{~h}$ with constant stirring and dialysed against $0 \cdot 1 \mathrm{M}$-potassium phosphate buffer, $\mathrm{pH} 6 \cdot 8$. The enzyme was inactivated by heating the mixture at $100{ }^{\circ} \mathrm{C}$ for $20 \mathrm{~min}$.

Binding of concanavalin A to glycolipoprotein. GLP with bound concanavalin A (Con A) was prepared according to the method of Gilboa-Garber \& Mizraki (1981). GLP rehydrated in PBS at pH 7.0 was incubated with an equal volume of Con A (Sigma) at a concentration of $2 \mathrm{mg} \mathrm{ml}^{-1}$ under sterile conditions at room temperature for $5 \mathrm{~h}$.

\section{RESULTS AND DISCUSSION}

\section{Biological effects of degrading the carbohydrate moiety of the GLP}

Selective destruction of monosaccharides by periodate oxidation has been frequently applied to the problem of analysing complex carbohydrates and glycoproteins (Spiro, 1966). However, we found this technique did not allow determination of what, if any, contribution the sugar residues of GLP make to the expression of lethality. The degree of sugar destruction resulting from the treatment could be assessed by the indirect-haemagglutination assay because the carbohydrate moiety of the GLP contains the antigenic determinants of the molecule (Koepp et al., 1981 a). Thus, periodate treatment reduced the inhibitory capacity of the GLP by $25 \%$ (Fig. 
Table 1. Reduction of lethal activity of GLP in mice by treatment degrading or blocking mannose residues

Mice were challenged with the $\mu \mathrm{g}$ equivalent of untreated GLP per $\mathrm{g}$ of mouse. The results represent two to five experiments.

$\begin{array}{lcccccc}\text { Treatment or GLP } & \begin{array}{c}\text { Challenge dose } \\ \text { fragment }\end{array} & \begin{array}{c}\text { Total number of } \\ \text { surviving mice* }\end{array} \\ \text { None } & \text { g of mouse) } & 0 & 24 & 48 & 72 \\ & 40 & 10 & 7(3 \cdot 5) & 5(2 \cdot 5) & 4(2 \cdot 0) \\ & 50 & 25 & 12(2 \cdot 4) & 8(1 \cdot 6) & 7(1 \cdot 4) \\ \alpha \text {-Mannosidase } & 80 & 10 & 0(0 \cdot 0) & 0(0 \cdot 0) & 0(0 \cdot 0) \\ & 40 & 10 & 8(4 \cdot 0) & 3(1 \cdot 5) & 3(1 \cdot 5) \\ \text { Con A } & 80 & 10 & 8(4 \cdot 0) & 1(0 \cdot 5) & 1(0 \cdot 5) \\ \text { Glycolipid fragment } & 50 & 25 & 22(4 \cdot 4) & 12(2 \cdot 4) & 11(2 \cdot 2) \\ \text { PBS control } & 80 & 25 & 20(6 \cdot 7) & 10(3 \cdot 3) & 10(3 \cdot 3) \\ & 0 & 25 & 25(5 \cdot 0) & 25(5 \cdot 0) & 25(5 \cdot 0)\end{array}$

* The numbers in parentheses indicate the mean number of surviving mice in individual experiments.

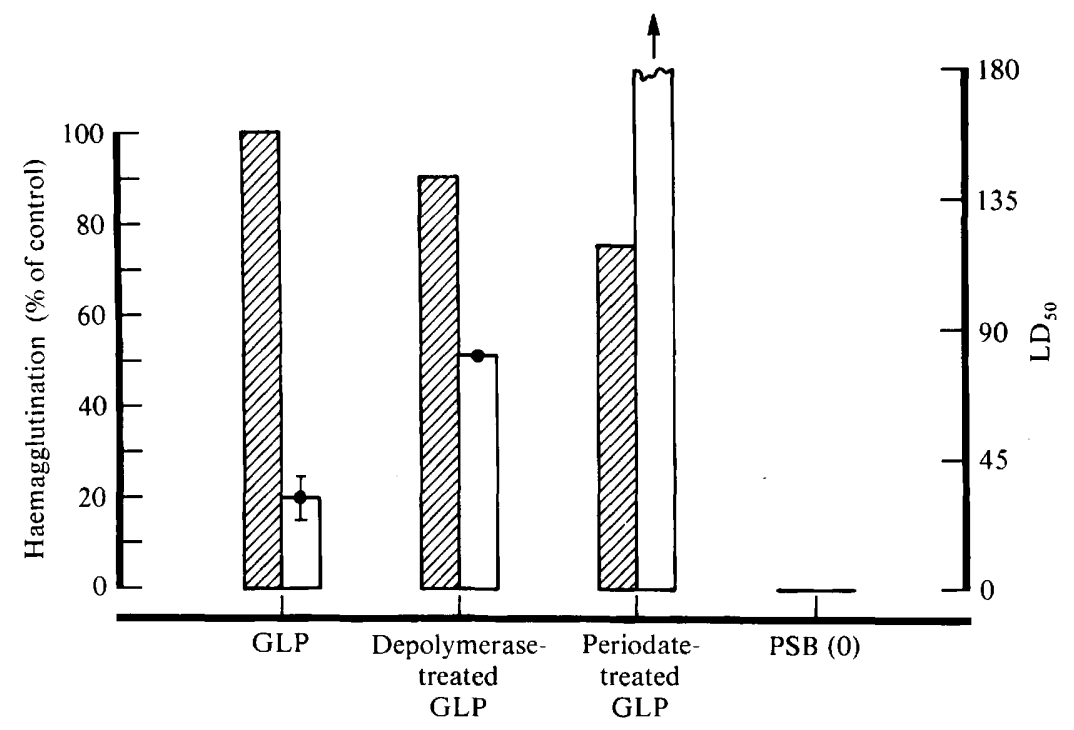

Fig. 1. Effect of periodate and depolymerase degradation of GLP on its capacity to inhibit indirect passive haemagglutination by anti-GLP serum (hatched columns) and on lethality as measured by LD $_{50}$ (open columns). The bar represents the standard error.

1) and at the highest concentrations tested, the periodate-degraded GLP was not lethal (Table 1). Furthermore, sublethal manifestations of toxicity such as ruffled coat and ocular discharge were not observed.

The specific substrate of the phage 2-induced polysaccharide depolymerase resides in the GLP of strain BI (Castillo \& Bartell, 1974). Consequently, the depolymerase appeared more suitable than periodate oxidation to the controlled exclusion of monosaccharide participation in the biological effects of the GLP. The extent of carbohydrate degradation of the depolymerasetreated GLP was determined by indirect haemagglutination inhibition (Fig. 1). The inhibitory capacity of the GLP was reduced by $10 \%$, indicating mild degradation; however, this was sufficient to reduce the lethality of the GLP by more than $60 \%$. These experiments supported the view that the carbohydrate moiety of the GLP was intimately involved with the expression of GLP lethality. Therefore, we attempted to establish which monosaccharide components of the carbohydrate were responsible for this phenomenon. 


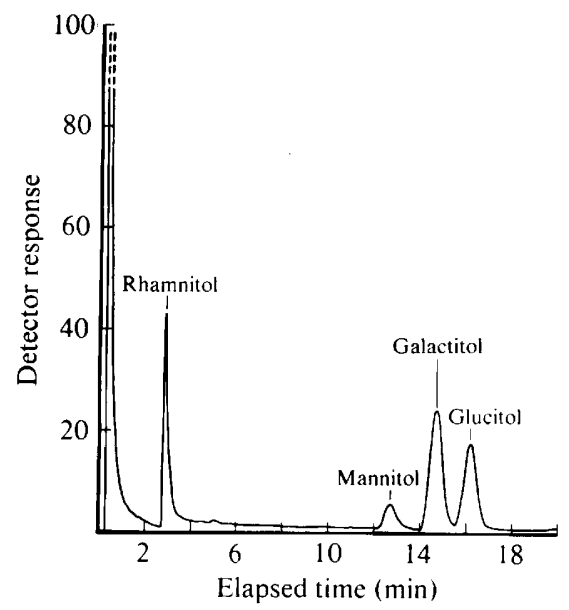

Fig. 2. GLC of aditol acetates of the neutral sugars in an acid hydrolysate of the GLP polysaccharide moiety.

\section{Neutral sugar composition of the polysaccharide moiety of GLP}

The first reported chemical analysis of the GLP from strain BI showed rhamnose, galactose, glucose and mannose as the neutral-sugar components (Bartell et al., 1970; Castillo \& Bartell, 1974). Recently the polysaccharide moiety of the GLP has been isolated in a lipid-free and protein-free form (Koepp et al., 1981a). However, the individual neutral-sugar components of the isolated moiety were not identified. We analysed these by GLC and found that all neutral sugars originally identified in GLP were retained in the isolated polysaccharide (Fig. 2).

\section{Effect of neutral sugars on the activity of anti-GLP serum}

Antiserum to GLP agglutinates sheep erythrocytes coated with GLP, and the agglutination is inhibited by low levels of GLP (Sensakovic \& Bartell, 1974). Individual neutral sugars may specifically inhibit antibody binding, when they are introduced in low concentration into systems where they are known to be the immunodeterminant. For example, binding of specific antiserum to the cell wall polysaccharide antigens of the beta-hemolytic steptococci is inhibited by $N$-acetylglucosamine (Coligan et al., 1978). Thus, we investigated the effect of the individual constituent neutral sugars of GLP on the indirect haemagglutinating activity of anti-GLP serum (Fig. 3). D-Mannose and D-mannosamine $\mathrm{HCl}$ inhibited the haemagglutination by $75 \%$, while $25 \%$ inhibition was obtained with glucose and rhamnose. Galactose did not inhibit. Yeast mannan, a soluble polymeric component of the cell walls (Phaff, 1963), showed an inhibitory activity $(88 \%)$ only exceeded by GLP $(98 \%)$.

The effect of anti-GLP serum on yeast cells was examined, since anti-GLP serum might interact directly with yeast cells, if the immunodeterminant sugar of GLP was indeed mannose. This was the case, and macroscopically visible aggregates were formed which were absent when normal control serum was used. Similar aggregates appeared when anti-polysaccharide serum was substituted for the anti-GLP serum. On the other hand, antiserum to the glycolipid moiety did not aggregate the yeast cells. This result was consistent with the hypothesis that mannose is the principal immunodeterminant, since the glycolipid moiety, although containing the other neutral sugars of the native GLP, does not contain mannose among its constituent sugars (Koepp et al., 1981 b)

\section{Mannose and the expression of GLP lethality}

We have proposed that mannose may be required for the expression of GLP toxicity (Koepp et al., 1981 b). This prompted a series of experiments in which the mannose of the GLP was degraded or sterically blocked, and the effects on GLP lethality were determined. 


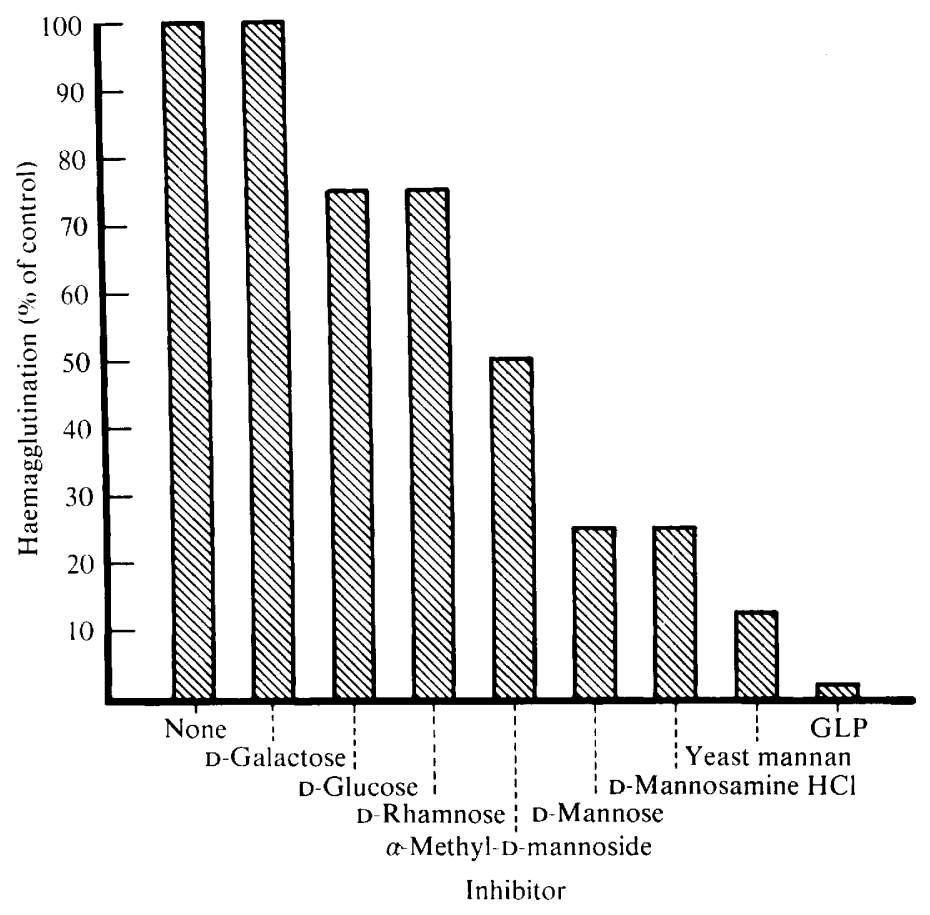

Fig. 3. Inhibition of indirect passive-haemagglutinating capacity of anti-GLP serum by monosaccharides, yeast cell wall mannan and native GLP.

$\alpha$-Mannosidase was used in an attempt to specifically degrade the terminal mannose residues without further disruption of the GLP. This treatment did not significantly affect the lethality of the GLP at challenges near the $50 \%$ lethal dose ( $40 \mu \mathrm{g}$ per g of mouse); however, at challenges twofold higher $(80 \mu \mathrm{g}$ per $\mathrm{g}$ of mouse), the lethality at $24 \mathrm{~h}$ was significantly reduced $(P<0.01)$ (Table 1). Con A specifically binds to surface mannose and glucose residues (Sharon \& Lis, 1972); accordingly, it provided a simple means for sterically blocking mannose terminal residues on the GLP. GLP treated with Con A was significantly less lethal than untreated GLP at $24 \mathrm{~h}(P$ $<0.01$ ) (Table 1). On subsequent days, the lethality of both forms of treated GLP remained less than that of the native GLP, but the differences were not statistically significant. We concluded that, although the possibility of glucose participation was not entirely excluded, interference with the expression of the biological activity of surface mannose at the very least retarded the onset of lethality. Apparently, an additional mediator exists for the expression of lethality, since a sharp increase in the number of deaths occurred after $24 \mathrm{~h}$ and the $\alpha$-mannosidase treatment did not effectively reduce lethality at doses equivalent to the $\mathrm{LD}_{50}$ value for the native GLP. The additional mediator may be glucose or rhamnose. Both these sugars are present in native GLP in greater amounts than mannose (Fig. 2) and both exerted some inhibitory effect against the indirect haemagglutinating activity of anti-GLP serum (Fig. 3).

Our conclusions led us to re-examine our previous results on the lethality of the glycolipid (Koepp et al., 1981 b). Lethality in those studies was expressed as $\mathrm{LD}_{50}$, based on the survival of mice $5 \mathrm{~d}$ after the challenge injection. The injection of $80 \mu \mathrm{g}$ of the glycolipid fragment per $\mathrm{g}$ of mouse showed the course of lethality (Table 1). The principal lethal effect occurred after the first $24 \mathrm{~h}$ period, whereas with native GLP the principal effect occurred by $24 \mathrm{~h}$. The possibility cannot be discounted that the degradative procedures used to isolate the glycolipid fragment had effects other than the removal of mannose that retarded the expression of lethality. Nevertheless, in the light of other results reported here, the absence of mannose from the 
glycolipid (Koepp et al., 1981 b) provides some additional evidence supporting the role of mannose as an effector of lethality.

We concluded that the carbohydrate moiety is required for full expression of the lethality of the lipid moiety. Mannose appeared to be the principal mediator, with glucose or rhamnose or both possibly contributing additional mediation. The mechanism for the mediation is completely unknown. The simplest explanation may be that the carbohydrate of the bacterial surface binds to the host tissue, thus allowing the lipid moiety to remain in place long enough for it to exert its characteristic lethal toxicity. The host cell involved could very well be the neutrophil, and the mechanism could be anti-phagocytosis; neutropenia follows injection of GLP which selectively associates with neutrophils in mice (Lynn et al., 1977). The results reported here offer an explanation of the molecular basis of the immunoprotective capacity of anti-GLP serum against challenge with viable $P$. aeruginosa (Sensakovic \& Bartell, 1974). The anti-GLP serum may neutralize the effector function of the monosaccharide residues in the lethal challenge.

Clearly, the mechanism involved here is not that of the adhesins widely reported for many bacterial species (Ofek et al., 1978). Adhesins consist of lectin-like fimbriae on the bacterial surface that adhere to mannose residues acting as receptors on the host cell, whereas in the present results the monosaccharide residues were located on the bacterial surface. A similar phenomenon was reported by Freimer et al. (1978) who showed that analogues of several bacterial wall monosaccharides blocked the binding of various Gram-negative bacteria, including $P$. aeruginosa to cultured polymorphonuclear leucocytes. However, mannose did not inhibit binding. If this lack of activity is due to differences in the $P$. aeruginosa strains used, then our results were consistent with theirs. Freimer et al. (1978) suggested that carbohydratemediated binding may facilitate the invasiveness of a pathogenic organism by maintaining the organisms in contact with the host tissue long enough to increase penetration of the cell. This sequence may underlie the events in the $P$. aeruginosa experimental infection, with the carbohydrate of the GLP providing the initial contact with the host cell.

We have suggested here that carbohydrate mediation of GLP lethality may be effected through adherence and damage to phagocytic cells. However, the specific host tissue with which the GLP carbohydrate interacts remains to be identified. Until that is accomplished it will not be possible to define the underlying mechanisms with precision, nor even to relate the present phenomenon confidently to other forms of surface-mediated virulence factors.

This research was supported by Public Health Service grant number AI-08504 from the National Institute of Allergy and Infectious Disease.

\section{REFERENCES}

Bartell, P. F., OrR, T. E. \& LaM, G. K. H. (1966) Polysaccharide depolymerase associated with bacteriophage infection. Journal of Bacteriology 92, 5662 .

Bartell, P. F., Orr, T. E. \& Chudio, B. (1970). Purification and chemical composition of the protective slime antigen of Pseudomonas aeruginosa. Infection and Immunity 2, 543-548.

Batson, H. C. (1956). An Introduction to Statistics in the Medical Sciences. Minneapolis: Burgess Publishing Co.

Castillo, F. J. \& Bartell, P. F. (1974). Studies on the bacteriophage 2 receptor of Pseudomonas aeruginosa. Journal of Virology 14, 904-909.

Coligan, J. E., Fraser, B. A. \& Kindt, T. J. (1978). Immunochemistry of streptococcal group $C$ polysaccharide and the nature of its cross-reaction with the Forssman glycolipid. Progress in Clinical Biology Research 23, 601-612.
Doggett, R. G. (editor) (1979). Pseudomonas aeruginosa: Clinical Manifestations of Infection and Current Therapy. New York: Academic Press.

Fenson, A. H. \& Gray, G. W. (1969). The chemical composition of the lipopolysaccharide of Pseudomonas aeruginosa. Biochemical Journal 114, 185196.

Freimer, N. B., ÖgMundSdottir, H. M., BlackWELl, C. C., Sutherland, I. W., Graham, L. \& Weir, D. M. (1978). The role of cell wall carbohydrates in binding of microorganisms to mouse peritoneal exudate macrophages. Acta pathologica et microbiologica scandanarica $\mathbf{B 8 6}, 53-57$.

Gilboa-Garber, N. \& Mizraki, L. (1981). Binding of Pseudomonas aeruginosa lectin to Rhizobium sp. Journal of Applied Bacteriology 50, 21-28.

HAYNes, W. C. (1951). Pseudomonas aeruginosa its characterization and identification. Journal of General Microbiolog. 5, 939-950. 
Koepr, L. H., OrR, T. \& Bartell, P. F. (1981a). Polysaccharide of the slime glycolipoprotein of Pseudomonas aeruginosa. Infection and Immunity 33, 788-794.

Koepr, L. H., ORR, T. \& Bartell, P. F. (1981 b). The lethal moiety of the surface slime glycolipoprotein of Pseudomonas aeruginosa. Current Microbiology 6, 383-388.

Kozel, T. R. \& CAZIN, J., JR (1974). Induction of humoral antibody response by soluble polysaccharide of Cryptococcus neoformans. Mycopathologia et mycologia applicata 54, 21-30.

LynN, M., Sensakovic, J. W. \& Bartell, P. F. (1977). In civo distribution of Pseudomonas aeruginosa slime glycolipoprotein association with leukocytes. Infection and Immunity 15, 109-114.

Maisch, P. A. \& Calderone, R. A. (1981). Role of surface mannose in the adherence of Candida albicans to fibrin-platelet clots formed in vitro. Infection and Immunity 32, 92-97.

OfEK, I., Beachey, E. H. \& SHaRon, N. (1978). Surface sugars of animal cells as determinants of recognition in bacterial adherence. Trends in Biochemical Science 3, 159-160.

PhafF, H. J. (1963). Cell wall of yeasts. Annual Review of Microbiology 17, 15-30.

REED, L. J. \& MUENCH, H. (1938). A simple method of estimating fifty percent end points. American Journal of Hygiene 27, 493-497.

Sensakovic, J. W. \& Bartell, P. F. (1974). The slime of Pseudomonas aeruginosa: biological characterization of possible role in experimental infection. Journal of Infectious Diseases 129, 101-109.

Sensakovic, J. W. \& Bartell, P. F. (1975). Biological activity of fragments derived from the extracellular slime glycolipoprotein of Pseudomonas aeruginosa. Infection and Immunity 12, 808-812.

Sharon, N. \& LIs, H. (1972). Lectins: cell-agglutinating and sugar-specific proteins. Science 177, 949959.

SPIRO, R. G. (1966). Analysis of sugars found in glycoproteins. Methods in Enzymology 18, 26-52.

SPIRO, R. G. (1972). Study of the carbohydrate of glycoproteins. Methods in Enzymology 28, 3-43. 